\title{
VALUASI EKONOMI DAMPAK KEMACETAN LALU-LINTAS DI DKI JAKARTA
}

\section{Economic Valuation of The Impact of Traffic Congestion In DKI Jakarta}

\author{
Yusman Syaukat', Ma'mun Sarma², A. Faroby Falatehan', dan Rizal Bahtiar1 \\ 1 Staff Pengajar Departemen Ekonomi Sumberdaya dan Lingkungan.Fakultas Ekonomi dan Manajemen IPB \\ E-mail: ysyaukat@gmail.com,f_falatehan@hotmail.com,rizal.b.ipb@gmail.com \\ 2 Staff Pengajar Departemen Manajemen. Fakultas Ekonomi dan Manajemen IPB \\ E-mail: mamun_sarma@yahoo.com.
}

\begin{abstract}
ABSTACT
Congestion that occurs in the Sudirman area of economic impact on society. Congestion can lead to a reduction in income and decrease the economic benefits for workers who work in the Sudirman. The decline in the perceived economic benefits of the workers can be called with a loss. Losses felt by workers is the value of wasted fuel loss due to increased purchases of fuel oil (BBM), a decrease in productivity in the form of wasted time akbitat jammed seen from income and working time. In addition, there is a loss of value where there is a decline in the health of the costs incurred for treatment due to declining health and psychological pressure value losses due to traffic. Total economic losses due to the impact of congestion on Jl. Sudirman Rp 19,716,239,573,128 / year. The loss is derived from the value of inefficiency fuel oil (BBM) Rp 15,008,423,787,414 / year, the value of reductions in labor productivity $R p$ 2,871,644,285,714 / year, the value of psychological distress as a result of congestion Rp 525.800.000.000/tahun, and health value of USD 1,310,371,500,000 / year.
\end{abstract}

Key word : Congestion, Economic Losses, Inefficiency, Jakarta

\begin{abstract}
ABSTRAK
Kemacetan yang terjadi di Jakarta, khususnya di daerah Jalan Sudirman berpengaruh pada ekonomi masyarakat. Kemacetan ini telah berdampak pada pengurangan penghasilan dan penurunan manfaat ekonomi bagi pekerja yang bekerja di daerah Sudirman. Kerugian yang sangat dirasakan para pekerja adalah nilai kerugian dari pemborosan bahan bakar akibat peningkatan pembelian bahan bakar minyak (BBM), penurunan produktivitas berupa waktu yang terbuang akibat kemacetan. Selain itu, kemacetan lalu-lintas juga menimbulkan kerugian nilai ekonomi akibat penurunan kondisi kesehatan, sehingga menimbulkan biaya dalam bentuk biaya pengobatan, serta kerugian nilai tekanan psikologis karena kemacetan. Kerugian total ekonomi akibat dampak kemacetan di Jl. Jenderal Sudirman tersebut mencapai Rp 19.72 trilyun per tahun atau sekitar 1,6 persen dari nilai PDRB DKI Jakarta. Kerugian tersebut sebagian besar berasal dari kerugian akibat: inefisiensi Bahan Bakar Motor (BBM) (76 persen), penurunan produktivitas pekerja (15 persen), peningkatan biaya kesehatan (7 persen), serta kerugian akibat tekanan psikologis (3 persen).
\end{abstract}

Kata Kunci: Kerugian ekonomi, metoda valuasi, inefisiensi

\section{PENDAHULUAN}

\section{Latar Belakang}

Jakarta adalah ibukota negara dan pusat pemerintahan Indonesia. Wilayah Jakarta seluas 7.659,02 km² dengan jumlah penduduk 8.525.109 jiwa, maka DKI Jakarta memiliki kepadatan penduduk yang sangat tinggi yaitu mencapai 19.537 orang $/ \mathrm{km}^{2}$. Peningkatan penduduk dan pertumbuhan ekonomi telah mendorong kebutuhan infrastruktur yang terus meningkat. 
\begin{tabular}{cccc}
\hline Kemacetan di & Jakarta dalam 10 \\
tahun & belakangan & ini & semakin
\end{tabular} memperihatinkan. Beberapa penyebab utama, yakni tingginya angka penggunaan kendaraan pribadi, pertumbuhan ruas jalan yang tidak seimbang dengan laju pertumbuhan kendaraan dan kurangnya disiplin berlalu lintas. Menurut Pradeep, et al (2008), membangun jalan baru atau peningkatan kapasitas jalan yang ada merupakan cara untuk mengurangi kemacetan yang pada umumnya memerlukan biaya yang mahal. Selain itu, peningkatan kapasitas dapat menjadi permintaan laten akan penghematan waktu perjalanan. Banyak yang sepakat bahwa daerah tidak bisa terus membangun jalan untuk keluar dari kemacetan, sehingga manajemen permintaan adalah kuncinya.

Sumber utama dari kemacetan dikarenakan jumlah kendaraan yang melebihi kapasitas. Hal ini dapat terjadi karena dari tahun ke tahun jumlah kendaraan selalu meningkat, baik itu kendaraan roda dua, kendaraan umum maupun kendaraan penumpang umum. Selain itu kegagalan kebijakan juga memberikan dampak terhadap kemacetan seperti gagalnya membatasi perizinan jumlah kendaraan yang ada (Falatehan, 2010).

Badan Pusat Statistik (2010) memaparkan bahwa produksi kendaraan bermotor untuk kuartal II-2010 mengalami kenaikan 26,15 persen dibanding periode yang sama tahun sebelumnya. Sedangkan untuk produksi alat transportasi selain roda empat atau lebih mengalami kenaikan 19,23 persen. Tabel 1 menunjukkan peningkatan jumlah kendaraandi Jakarta dari tahun 2005 hingga-2010 setiap tahunnya.

Tabel 1. Jumlah Kendaraan Bermotor dari Tahun 2005-2010 di Provinsi Jakarta

\begin{tabular}{rrrrrrr}
\hline \multirow{2}{*}{ No } & \multirow{2}{*}{ Tahun } & \multicolumn{5}{c}{ Tipe Kendaraan } \\
\cline { 3 - 7 } & & Kendaraan Penumpang & Angkutan Barang & Bus & Sepeda Motor & Total \\
\hline \multirow{2}{*}{2} & \multirow{2}{*}{2006} & $1,454,286$ & 405,105 & 255,886 & $2,908,670$ & $5,023,947$ \\
3 & 2007 & $1,499,610$ & 405,836 & 256,207 & $3,242,090$ & $5,403,743$ \\
4 & 2008 & $1,547,336$ & 414,278 & 256,766 & $3,579,622$ & $5,798,002$ \\
5 & 2009 & $1,610,915$ & 427,359 & 257,370 & $3,968,749$ & $6,264,393$ \\
6 & 2010 & $1,661,795$ & 435,654 & 257,905 & $4,333,559$ & $6,688,913$ \\
\hline
\end{tabular}

Sumber: Dinas Perhubungan, 2011

Kemacetan di Jakarta berdampak juga terhadap pencemaran lingkungan, seperti adanya peningkatan emisi Gas Rumah Kaca (GRK) yang berasal dari kendaraan bermotor. Pencemaran udara diartikan sebagai adanya bahan-bahan atau zat-zat asing di dalam udara yang menyebabkan perubahan susunan (komposisi) udara dari keadaan normalnya. Kehadiran bahan atau zat asing di dalam udara dalam jumlah tertentu serta berada di udara dalam waktu yang cukup lama akan mengganggu kehidupan manusia, hewan, dan tumbuhan. Pembangunan yang berkembang pesat dewasa ini, khususnya dalam industri dan teknologi, serta meningkatnya jumlah kendaraan bermotor yang menggunakan bahan bakar fosil menyebabkan udara menjadi tercemar oleh gas-gas buangan hasil pembakaran (Wardhana, 2004).

Berdasarkan hasil penelitian yang dilakukan di Amerika Serikat pada tahun 1980, kematian yang disebabkan oleh pencemaran udara mencapai angka kurang lebih 51.000 orang. Menurut para ahli, pada sekitar tahun 2000-an kematian yang disebabkan oleh pencemaran udara akan mencapai angka 57.000 orang per tahunnya. Selama 20 tahun angka kematian yang disebabkan oleh pencemaran udara naik mendekati $14 \%$ atau mendekati $0,7 \%$ per tahun. Selain itu kerugian materi yang disebabkan oleh pencemaran udara, apabila diukur dengan uang, dapat mencapai sekitar 12-16 juta US dollar per tahun (Wardhana, 2004) 
Kerugian ekonomi baik secara tangible (nyata) maupun intagible (tidak nyata) akibat kemacetan terus dirasakan oleh para pengemudi atau pemilik kendaraan. Kerugian ekonomi akibat kemacetan akan memberikan dampak terhadap kondisi ekonomi makro daerah, dimana tingkat inflasi akan terjadi seiring meningkatnya harga transport akibat kemacetan. Jurnal ini memberikan gambaran berapa besar dampak ekonomi akibat kemacetan yang diperoleh dari nilai ekonomi pemborosan bahan bakar, penurunan produktivitas, dan tingkat stress.

\section{METODE PENELITIAN}

Objek penelitian dalam penelitian ini adalah orang yang mengendarai kendaraan pribadi dan lingkungan. Oleh karena itu penelitian ini akan banyak menggunakan teknik wawancara dalam pengumpulan datanya dan sebagian kecil dengan menggunakan alat bantu pengukuran emisi. Penelitian ini bertempat di Provinsi DKI Jakarta, adapun area penelitian meliputi area Blok M-Stasiun Kota, Jalan Gatot Subroto (dari KuninganSenayan), Rasuna Said-Tendean, TendeanBlok M dan Asia Afrika-Pejompongan.

Metode valuasi ekonomi sumberdaya dan lingkungan akan digunakan dalam perhitungan kerugian akibat kemacetan.

1) Nilai kerugian pemborosan bahan bakar. Nilai ini didekati dengan menggunakan ukuran rata-rata dan biaya bahan bakar terbuang dikalikan dengan jumlah total kendaraan di Jakarta. Perhitungan ini akan dibedakan berdasarkan area kemacetan dan asal kendaraan bermotor yang akan dibagi menjadi 4 yaitu berasal dalam Jakarta dan Depok, dari wilayah Tanggerang, dari wilayah Bekasi, dan dari wilayah Bogor.

$$
V G f=\frac{\sum_{n=1}^{n} G i}{n} \cdot \frac{\sum_{n=1}^{n} T l}{n} . V P
$$

Keterangan

VGf = Nilai inefisiensi bahan bakar

$\mathrm{Gi}=$ Jumlah bahan bakar yang

dikeluarkan per jam

$\mathrm{Tl}=$ Lama waktu macet

VP = Populasi mobil pribadi

2) Penurunan produktivitas.

Penurunan produktivitas dihitung berdasarkan rumus sebagai berikut:

$$
C P V=\frac{\sum_{i=1}^{n} T L}{n}\left(\frac{\sum_{i=1}^{n} I}{n} \frac{1}{\sum_{i=1}^{n} T W}\right) \sum W \sum D W
$$

Keterangan:

$$
\begin{array}{ll}
\text { CPV } & =\text { Nilai produktivitas yang hilang } \\
\text { TL } & =\text { Waktu yang terbuang karena macet } \\
\text { I } & =\text { Pendapatan per hari } \\
\text { TW } & =\text { Waktu kerja per hari } \\
\text { W } & =\text { Jumlah pekerja di area penelitian } \\
\text { DW } & =\text { Hari kerja per tahun }
\end{array}
$$

3) Nilai penurunan kesehatan.

Perhitungan penurunan kesehatan ini akan dihitung dengan mengumpulkan data biaya berobat masyarakat yang terkena Infeksi Saluran Pernafasan Atas (ISPA) dari beberapa rumah sakit atau puskesmas di daerah tersebut.

4) Nilai tekanan psikologis (stress) karena kemacetan. Nilai ini akan didekati dengan biaya yang dikeluarkan setiap bulannya untuk berlibur. Adapun perhitungannya dengan menggunakan rumus sebagai berikut:

$$
C S T=\left(\frac{T L}{T L+T W} 100 \%\right) \frac{\sum_{i=1}^{n} C H_{t}}{n} \sum W
$$

Keterangan:

$$
\begin{array}{ll}
\text { CST } & =\text { Nilai tekanan psikologis karena } \\
& \text { kemacetan } \\
\text { TL } & =\text { Waktu kemacetan } \\
\text { TW } & =\text { Waktu kerja } \\
\mathrm{CHt} & =\text { Biaya berlibur per tahun } \\
\mathrm{W} & =\text { Jumlah populasi yang terjebak macet }
\end{array}
$$




\section{HASIL DAN PEMBAHASAN}

\section{Karakteristik Responden}

Responden pada penelitian ini adalah pekerja yang melalui Jalan Sudirman untuk menuju lokasi tempat kerja responden. Karakteristik sosial ekonomi responden akan dijelaskan berdasarkan kriterian tertentu yang akan dipaparkan di bawah ini.

\section{Jarak Rumah ke Tempat Kerja}

Jarak rumah menuju tempat kerja responden beragam, ada yang relatif dekat dari rumah ada juga yang relatif jauh dari rumah. Banyaknya ragam jarak rumah masing-masing responden ke tempat kerja maka diklasifikasikan menjadi enam kelompok. Dimana jarak terdekat yaitu 0 hingga $10 \mathrm{~km}$ dan terjauh adalah 51 hingga $60 \mathrm{~km}$. Persentase terbesar jarak rumah responden menuju tempat kerja yaitu antara 0 hingga $10 \mathrm{~km}$ sebesar 38,57 persen. Hal ini menunjukkan bahwa jarak responden menuju tempat bekerja relatif dekat sehingga seharusnya tidak membutuhkan waktu yang lama untuk mencapai tempat kerja.

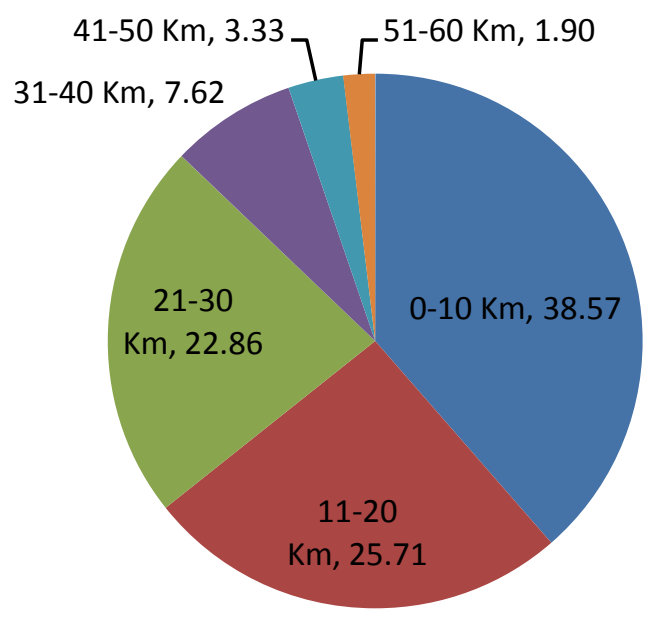

Sumber: Data Primer, 2013 (diolah)

Gambar 1. Jarak Rumah ke Tempat Kerja

\section{Waktu Tempuh}

Responden pengguna Jalan Sudirman merasakan perbedaan yang signifikan antara keadaan lalulintas beberapa tahun lalu dengan saat ini. Pada kondisi normal dengan asumsi jalan tidak macet, waktu tempuh yang diperlukan responden menuju tempat kerja hanya memerlukan waktu 0 hingga 36 menit sebesar 65 persen. Sedangkan pada kondisi macet waktu tempuh yang dibutuhkan responden menuju tempat kerja mencapai 31 hingga 60 menit sebesar 42 persen. Hal ini menunjukkan bahwa tingkat kemacetan sangat dirasakan dimana pada kondisi normal sebagian besar para pekerja menghabiskan waktu menuju tempat kerja hanya berkisar 0 hingga 30 menit. Namun, pada kondisi macet waktu tempuh meningkat menjadi 31 hingga 60 menit bahkan banyak yang menghabiskan waktu menuju ke tempat kerja lebih dari 60 menit. Hal tersebut menunjukkan bahwa kemacetan yang terjadi di Jalan Sudirman sangat merugikan para pekerja dalam hal waktu. 


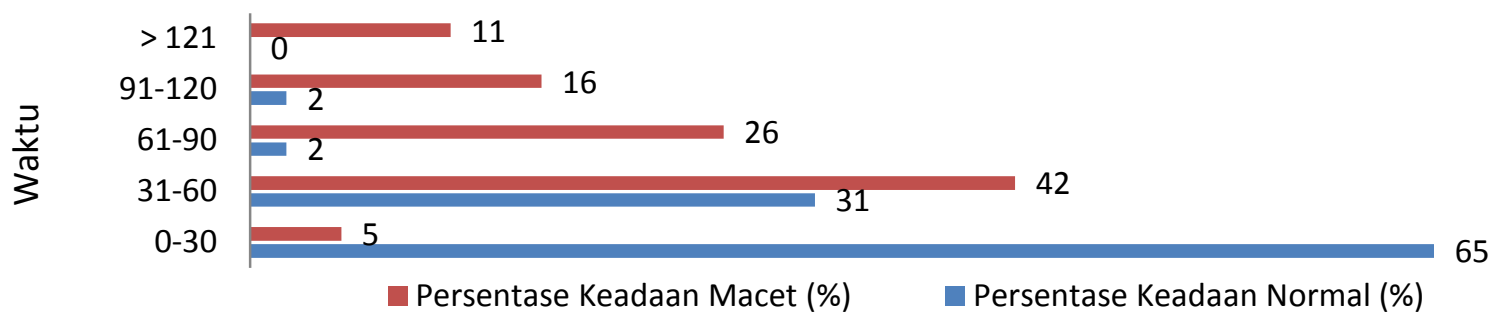

Sumber: Data Primer, 2013 (diolah)

Gambar 2. Waktu Tempuh Menuju Tempat Kerja pada KondisiNormal dan Macet

$\begin{array}{ll}\text { Rata-rata peningkatan waktu } & \text { dapat dilihat bahwa peningkatan waktu } \\ \text { tempuh akibat kemacetan di Jalan } & \text { tempuh yang sangat tinggi terdapat pada } \\ \text { Sudirman dilihat dari jarak rumah sampai } & \text { jarak } 50 \text { hingga } 60 \text { km yaitu sebesar } 115 \\ \text { tempat kerja dapat dilihat pada Gambar } & \text { menit. Hal tersebut sangat merugikan para } \\ \text { 3.Akibat kemacetan di Jalan Sudirman } & \text { pekerja dimana mereka harus berangkat } \\ \text { terdapat peningkatan waktu tempuh } & \text { dari rumah lebih pagi dan pulang ke rumah } \\ \text { terhadap jarak rumah responden sampai } & \text { terlambat dari jam yang seharusnya bisa } \\ \text { tempat kerja. Berdasarkan hasil penelitian, } & \text { lebih awal. }\end{array}$

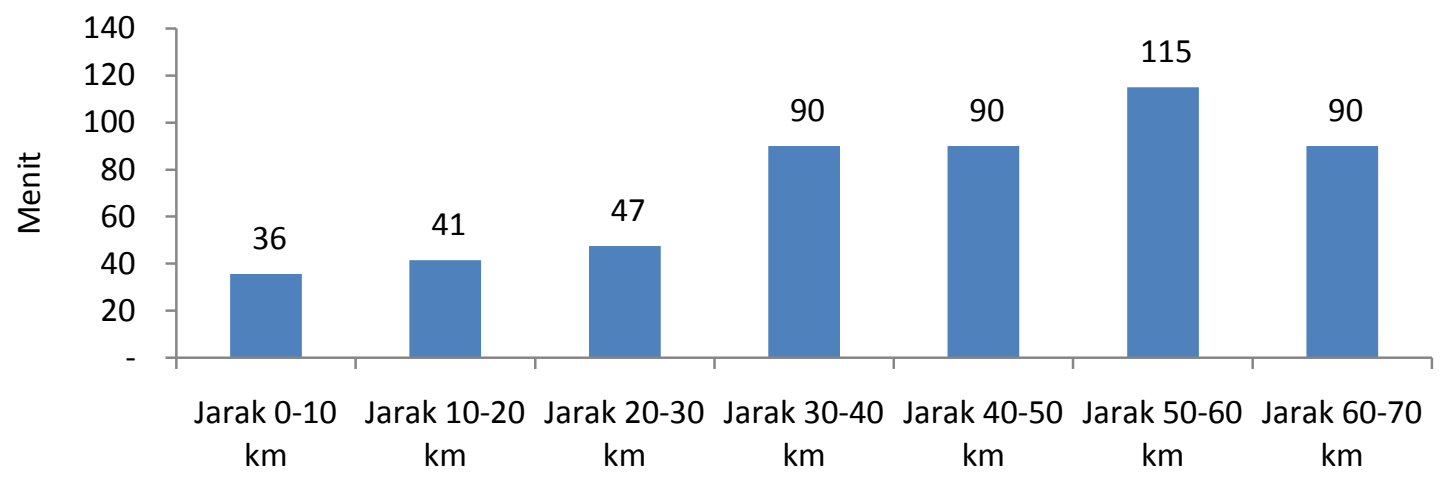

Sumber: Data Primer, 2013 (diolah)

Gambar 3. Rata-rata Peningkatan Waktu Tempuh Akibat Kemacetan di Jalan Sudirman

\section{Penurunan Produktivitas Pekerja}

Kemacetan yang terjadi setiap hari di Jalan Sudirman sangat berdampak pada para pekerja terutama dalam kerugian materi berupa uang yang dikeluarkan dan waktu.Kerugian materi yang dikeluarkan akibat kemacetan salah satunya adalah pembelian bahan bakar. Semakin lama waktu tempuh yang dihabiskan maka 74 bahan bakar yang diperlukan akan semakin banyak. Adapun peningkatan bahan bakar yang dikeluarkan responden dibandingkan pada keadaan normal dapat dilihat pada Gambar 4. Pada Gambar 4 terlihat bahwa pada saat kondisi normal sebanyak 158 responden menggunakan bahan bakar menuju tempat kerja 0 hingga 2 liter tetapi ketika terjadi kemacetan terjadi penurunan jumlah responden menjadi 7 hingga 8 . Hal ini disebabkan terdapat peningkatan penggunaan bahan bakar ketika terjadi kemacetan sebanyak 3 hingga 6 liter dan 7 hingga 8 liter. 


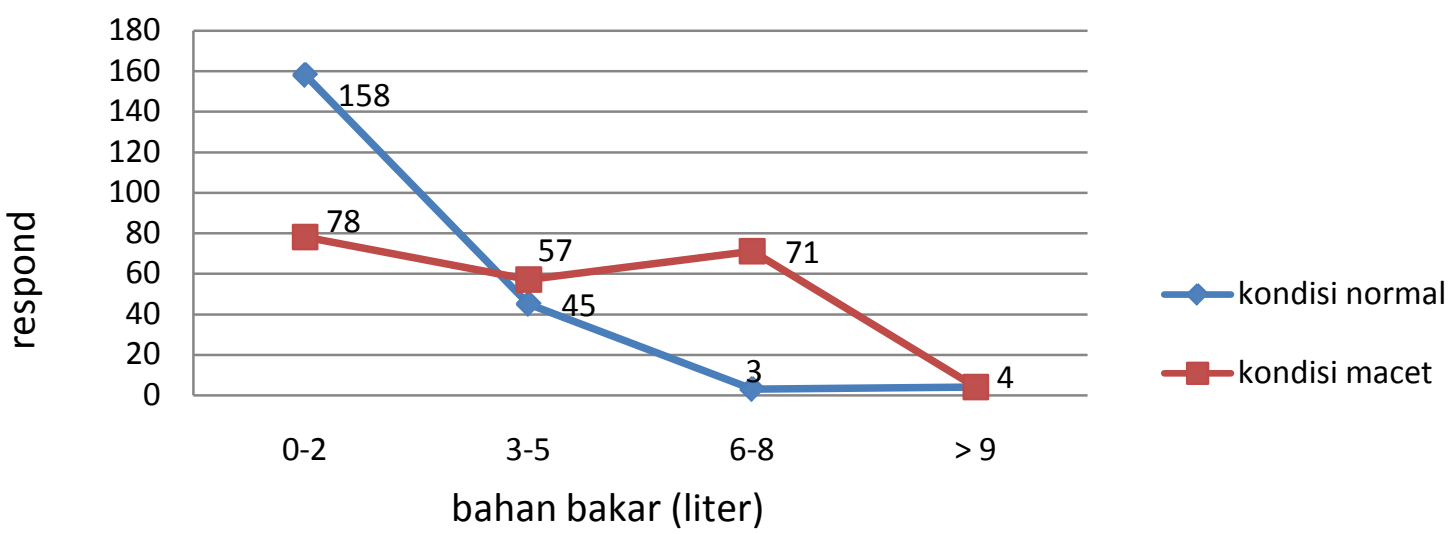

Sumber: Data Primer, 2013 (diolah)

Gambar 4. Rata-rata Perubahan Penggunaan Bahan Bakar

Akibat Kemacetan di Jalan Sudirman

Waktu yang hilang sangat luang dihabiskan untuk istirahat dirasakan oleh sebagian besar para pekerja. Kerugian ini sangat terlihat jelas ketika dibandingkan dengan kondisi normal. Pada kondisi normal para pekerja hampir sebagian besar masih memiliki waktu luang yang dapat dimanfaatkan sebelum memulai aktivitas pekerjaannya. Aktivitas yang dilakukan sebagian besar pekerja (42,86\%) dalam memanfaatkan waktu diantaranya, merokok, mengopi dan berdandan. Selain itu, ada juga yang digunakan untuk sarapan bagi pekerja yang belum sempat sarapan di rumah $(25,71 \%)$ dan membaca koran untuk mengetahui ibformasi terbaru (8,57\%). Sisanya digunakan untuk mempersiapkan berkasberkas kerja dan langsung digunakan untuk bekerja.

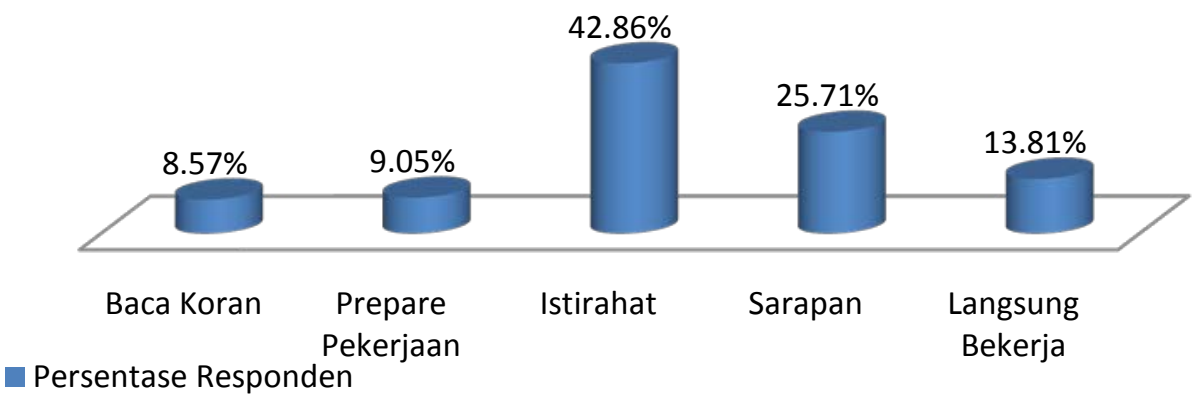

Gambar 5. Aktivitas Pekerja Sebelum Bekerja pada Kondisi Normal Sumber: Data Primer, 2013 (diolah)

Berdasarkan survei dilapang, kemacetan di Jalan Sudirman selain menyebabkan waktu tempuh lebih lama dan tingkat kerugian yang tinggi baik dari waktu maupun materi. Keterlambatan pun tidak jarang dialami oleh sebagian besar responden pengguna Jalan Sudirman. Tingkat keterlambatan akibat kemacetan di Jalan Sudirman sangat tinggi. Presentase tingkat keterlambatan yang dialami 
responden mencapai 80 persen dari semua responden. Kemacetan yang terjadi dikarenakan semakin meningkatnya jumlah kendaraan yang melalui Jalan Sudirman dan infrastruktur yang kurang tepat sehingga pada saat jam kerja terjadi kemacetan yang sulit untuk dibaurkan.

\section{Aktivitas Menghadapi Tekanan Psikologis Akibat Macet}

Tidak jarang para pekerja pada saat menuju tempat kerja mengalami tekanan psikologis akibat kemacetan di Jalan Sudirman. Berdasarkan survei, diketahui sebesar 88 persen pekerja mengalami tekanan psikologis baik menuju tempat kerja maupun pada saat pulang menuju rumah. Untuk mengurangi tingkat tekanan psikologis, banyak dari para pekerja yang melakukan berbagai aktivitas selama

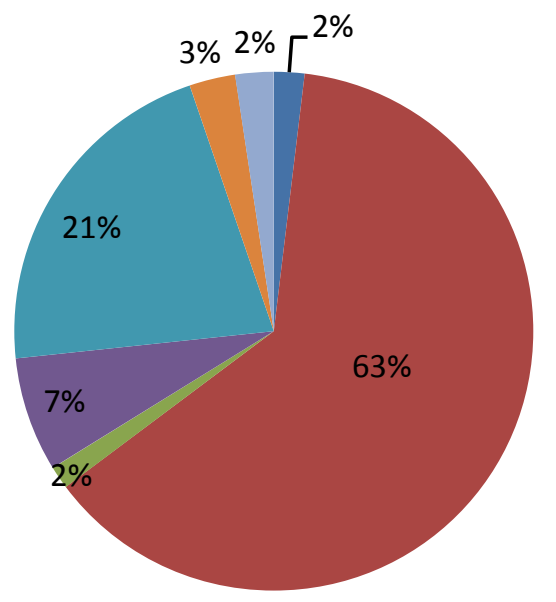

perjalanan menuju tempat kerja.Aktivitas yang dilakukan para pekerja diantaranya, membaca buku, mengoperasikan gadget, mengoperasikan laptop, istirahat (tidur), merokok, berbincang-bincang dan mengemil, akan tetapi aktivitas dominan yang dilakukan para pekerja untuk mengusir tekanan psikologis ini yaitu mengoperasikan gadget sebesar 63 persen dan merokok sebesar 21 persen. Aktivitas tersebut dominan disebabkan hampir semua pegawai memiliki gadget yang fleksibel dapat dibawa kemana-mana dan gadget memiliki aplikasi yang bermacammacam sehingga banyak dari pekerja dapat beraktivitas seperti mendengarkan musik, radio dan memanfaatkan media online seperti chatting, facebook, twitter dan lain sebagainnya.

Sumber: Data Primer, 2013 (diolah)

Gambar 6. Aktivitas Pekerja Menghadapi Tekanan Psikologis Akibat Kemacetan

Begitu juga ketika pulang kerja, untuk menghindari kemacetan menuju rumah para pekerja memiliki aktivitas untuk menghindari kemacetan meskipun banyak pekerja yang memutuskan langsung pulang ke rumah karena sudah berkeluarga. Adapun aktivitas yang biasa dilakukan pekerja untuk menghindari kemacetan saat pualng diantaranya makan bersama rekan kerja, mengambil lembur, hangoutbersama rekan kerja, istirahat di kantor. Persentase paling dominan dilakukan para pekerja untuk menghindari kemacetan yaitu makan bersama rekan kerja sebesar 27 persen. Aktivitas-aktivitas tersebut menjadi pilihan oleh para pekerja dengan tujuan utama untuk menghindari kemacetan. 


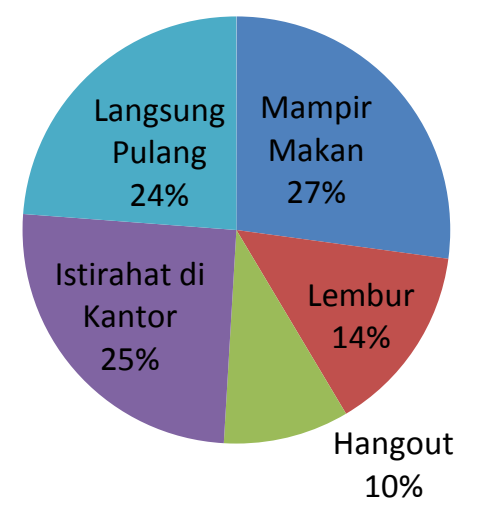

Sumber: Data Primer, 2013 (diolah)

Gambar 7. Aktivitas Pekerja Menghindari Kemacetan Saat Pulang Kerja

Tekanan psikilogis yang dialami para pekerja setiap harinya dalam rutinitas kerja membuat jenuh sebagian para pekerja. selain jenuh terhadap pekerjaan, para pekerja jenuh terhadap jalanan yang penat. Oleh karena itu, setiap akhir pekan banyak para pekerja yang ingin melepaskan kepenatannya baik berlibur (istirahat) di rumah maupun berwisata. Berdasarkan survei, peresentase terbesar para pekerja memilih berlibur di rumah yaitu sebesar 56 persen dan sisanya menghabiskan waktu untuk berlibur di luar rumah seperti, shopping, berwisata ke puncak dan berkunjung ke rumah saudara.

\section{Kerugian Ekonomi terhadap Pekerja di Sudirman}

Kemacetan yang terjadi di daerah Sudirman berpengaruh pada ekonomi masyarakat. Kemacetan dapat mengakibatkan pengurangan penghasilan dan menurunkan manfaat ekonomi bagi pekerja yang bekerja di Sudirman. Penurunan manfaat ekonomi yang dirasakan para pekerja dapat disebut dengan kerugian. Kerugian yang sangat dirasakan para pekerja adalah nilai kerugian pemborosan bahan bakar akibat peningkatan pembelian bahan bakar minyak (BBM), penurunan produktivitas berupa waktu yang terbuang akbitat macet dilihat dari pendapatan dan waktu kerja.Selain itu, terdapat kerugian berupa nilai penurunan kesehatan dimana terdapat biaya yang dikeluarkan untuk berobat akibat penurunan kesehatan dan kerugian nilai tekanan psikologis karena macet.

Kerugian akibat kemacetan yang terjadi di Sudirman meningkatkan pengeluaran biaya dimana biaya kerugian tersebut harus ditanggung oleh setiap pekerja yang bekerja di Sudirman. Ada pun tingkat kerugian ekonomi yang dirasakan para pekerja dapat diestimasi dengan perhitungan valuasi ekonomi.

\section{Nilai Ekonomi Pemborosan Bahan Bakar}

Kemacetan yang sering terjadi di Sudirman tidak hanya berdampak pada sisi sosial.Namun, pada sisi ekonomi juga. Kendaraan yang melaju pada saat lalu lintas normal akan mengkonsumsi BBM lebih hemat dari dibandingkan dengan konsumsi BBM pada saat macet. Meningkatnya pengeluaran biaya BBM ini merupakan kerugian yang harus ditanggung oleh setiap pekerja yang mnggunakan kendaraan pribadi.

Hasil penelitian terhadap 210 responden, responden menggunakan kendaraan pribadi berupa mobil dengan bahan bakar yang digunakan yaitu premium (82\%), pertamax (17\%) dan pertamax shell (1\%). Dalam menghitung nilai kerugian pemborosan bahan bakar dilakukan dengan pendekatan nilai 
inefisiensi bahan bakar yang dikeluarkan pada saat macet dikalikan dengan persentase jenis BBM yang digunakan pekerja dikalikan harga BBM yang digunakan. Asumsi harga bahan bakar yang digunakan untuk premium Rp 6.500 per liter, petamax Rp 9.600 per liter dan pertamax shell Rp 10.400 per liter. Dimana jumlah mobil yang ada di Jakarta sebanyak 4.449.020 unit.

Berdasarkan perhitungan diperoleh bahwa terdapat peningkatan rata-rata inefisiensi BBM terhadap masing-masing jenis bahan bakar yang digunakan. Pada bahan bakar pertamax peningkatan ratarata inefisiensi bahan bakar pada saat macet mencapai 2 liter, sedangkan pada bahan bakar premium mencapai 2 liter dan inefisiensi pada bahan bakar shell yaitu 3 liter. Diketahuinya peningkatan rata-rata inefisiensi bahan bakar maka dapat diperoleh jumlah pemborosan bahan bakar per tahun. Total pemborosan bahan bakar per tahun akibat kemacetan yaitu mencapai Rp 15.008.423.787.414. Secara tidak langsung pemborosan bahan bakar yang dikeluarkan setiap macet merupakan nilai kerugian yang ditanggung oleh para pekerja. Adapun rincian perhitungan pemborosan bahan bakar masing-masing jenis bahan bakar dapat dilihat pada Tabel 2.

Tabel 2. Estimasi Perhitungan Nilai Inefisiensi Bahan Bakar Akibat Kemacetan

\begin{tabular}{cccccc}
\hline BBM & Harga (Rp) & $\begin{array}{c}\text { Persentase Jenis } \\
\text { Pemanfatan BBM } \\
(\%)\end{array}$ & Jumlah Mobil & $\begin{array}{c}\text { Peningkatan } \\
\text { Rata-rata } \\
\text { Inefesiensi } \\
\text { BBM }\end{array}$ & $\begin{array}{c}\text { Jumlah Pemborosan } \\
\text { per Tahun }\end{array}$ \\
\hline Pertamax & 9600 & $17 \%$ & 756.333 & 2 & 3.683 .788 .560 .000 \\
Premium & 6500 & $82 \%$ & 3.648 .196 & 2 & 10.977 .611 .667 .414 \\
Shell & 10400 & $1 \%$ & 44.490 & 3 & 347.023 .560 .000 \\
\hline \multicolumn{2}{c}{ Jumlah } & $100 \%$ & 4.449 .020 & 6 & 15.008 .423 .787 .414 \\
\hline
\end{tabular}

Sumber: Data Primer, 2013 (diolah)

\section{Nilai Ekonomi Penurunan Produktivitas}

Kemacetan yang terjadi di Sudirman tidak hanya berdampak pada kerugian pemborosan bahan bakar tetapi berpengaruh pada penurunan produktivitas. Pekerja yang terjebak macet merasakan kerugian ekonomi yang besar apabila dibandingkan pada kondisi normal. Penurunan produktivitas yang dirasakan para pekerja berupa waktu yang hilang akibat macet dan pendapatan per hari. Akibat macet, sebagian besar responden kehilangan waktu luang yang biasanya dapat digunakan untuk istirahat, sarapan atau menyiapkan berkas-berkas untuk pekerjaannya sebelum memulai aktivitas pekerjaannya.

Berdasarkan penelitian diketahui bahwa rata-rata waktu responden yang terbuang akibat macet mencapai 2 jam. Dimana dalam satu hari rata-rata jam kerja mencapai 8 jam dengan pendapatanratarata per hari mencapai $\mathrm{Rp} 424.726$.
Penurunan produktivitas para pekerja akibat macet dapat diestimasi menggunakan pendekatan rata-rata waktu responden yang terbuang akibat macet dikalikan dengan rata-rata pendapatan per hari responden dikali satu per rata-rata waktu kerja responden per hari dikalikan jumlah pekerja di Sudirman dikali jumlah hari kerja pertahun dengan asumsi satu bulan terdapat 25 hari kerja. Adapun rincian perhitungan penurunan produktivitas pekerja akibat kemacetan dapat dilihat pada Tabel 3. 
Tabel 3. Estimasi Perhitungan Penurunan Produktivitas Pekerja Akibat Kemacetan

\begin{tabular}{lr}
\hline \multicolumn{1}{c}{ Komponen } & \multicolumn{1}{c}{ Nilai } \\
\hline Rata-rata waktu yang terbuang karena macet (jam) & 2 \\
Rata-rata pendapatan per hari (Rp) & 424.726 \\
Waktu kerja per hari (jam) & 8 \\
Jumlah pekerja di Sudirman (orang) & 165.000 \\
Hari kerja per tahun (hari) & 300 \\
Nilai produktivitas yang hilang (Rp/orang/bulan) & 17.403 .905 \\
\hline Nilai Produktivitas yang hilang dalam setahun & $\mathbf{2 . 8 7 1 . 6 4 4 . 2 8 5 . 7 1 4}$ \\
\hline
\end{tabular}

Sumber: Data Primer, 2013 (diolah)

Nilai produktivitas yang hilang dari pekerja di Sudirman akibat kemacetan per bulan mencapai Rp 17.403.905 per orang. Sehingga dalam satu tahun total nilai produktivitas yang hilang mencapai Rp 2.871.644.285.714. Nilai tersebut bukanlah nilai yang kecil. Oleh karena itu, perlu adanya campur tangan pemerintah setempat untuk mengatasi kemacetan yang terjadi untuk mengurangi kerugian yang dirasakan oleh para pekerja di Sudirman.

\section{Nilai Ekonomi Penurunan Kesehatan}

Kemacetan yang hampir setiap hari terjadi di Sudirman secara tidak langsung berdampak bagi pengguna jalan khususnya para pekerja yang melintasi daerah Sudirman.Akibat kemacetan yang terjadi dapat menurunkan tingkat kesehatan pengguna jalan. Pada saat macet terdapat peningkatan produksi asap sehingga semakin meningkatnya produksi asap maka banyak pengguna jalan yang menghirup karbon lebih banyak. Hal tersebut mengakibatkan banyak pengguna jalan yang mengalami menderita ISPA akibat polusi udara.

Berdasarkan data yang diperoleh dari dinas kesehatan Provinsi DKI Jakarta, 2012, diketahui jumlah penderita ISPA di Jakarta mencapai 873.581 orang. Rata-rata biaya yang dikeluarkan untuk berobat mencapai Rp 1.500.000. Sehingga total biaya yang dikeluarkan penderita akibat macet mencapai Rp 1.310.371.500.000. Biaya yang dikeluarkan untuk berobat merupakan kerugian yang ditanggung oleh pekerja akibat macet.Adapun rincian perhitungan biaya berobat yang dikeluarkan untuk pengobatan penyakit ISPA dapat dilihat pada Tabel 4.

Tabel 4. Biaya yang Dikeluarkan untuk Pengobatan ISPA Akibat Kemacetan

\begin{tabular}{clcc}
\hline No & Jumlah Penyakit ISPA & Penderita & Sumber \\
\hline \multirow{2}{*}{1} & Jumlah Penderita ISPA & 873.581 & Dinas Kesehatan Provinsi DKI Jakarta, \\
& Tahun 2012 & & 2012 \\
2 & $\begin{array}{l}\text { Rata-rata biaya di Rumah } \\
\text { Sakit }\end{array}$ & 1.500 .000 & $\begin{array}{c}\text { Estimasi Perkiraan Biaya dengan } \\
\end{array}$ \\
& Jumlah Biaya Per Tahun & $\mathbf{1 . 3 1 0 . 3 7 1 . 5 0 0 . 0 0 0}$ & Wawancara 15 Penderita ISPA \\
\hline
\end{tabular}

Sumber: Data Primer, 2013 (diolah)

\section{Nilai Ekonomi Tekanan Psikologis Akibat Kemacetan}

Kemacetan yang hampir setiap hari terjadi di Sudirman secara tidak langsung berdampak bagi psikis para pekerja yang melintasi daerah Sudirman saat berangkat maupun pulang kantor. Akibat kemacetan yang terjadi hampir setiap hari banyak pekerja yang mengalami tekanan psikologis saat perjalanan sehingga banyak para pekerja pada saat libur memanfaatkan waktu untuk berlibur yang bertujuan menghilangkan tekanan psikologis.

Nilai kerugian tekanan psikologis akibat macet dapat dihitung menggunakan pendekatan biaya yang dikeluarkan setiap tahunnya untuk berlibur dikalikan jumlah pekerja yang terjebak macet dikalikan dengan persetase rata-rata waktu kemacetan responden dibagi rata-rata 
waktu macet ditambah rata-rata waktu kerja. Adapun rincian perhitungan penurunan produktivitas pekerja akibat macet dapat dilihat pada Tabel 5.

Berdasarkanestimasi perhitungan diperoleh nilai tekanan psikologis dari pekerja akibat macet yaitu sebesar Rp 525.800.000.000 per tahun. Hal tersebut terlihat bahwa pekerja yang mengalami setres pada hari kerja sangat tinggi. Oleh karena itu, banyak para pekerja yang benar-benar mamanfaatkan waktu liburnya untuk melepas kejenuhan dengan berwisata, berkunjung ke saudara bahkan ada juga yang tidak ingin keluar dari rumah akibat jenuh melihat keramean terutama kemacetan yang setiap hari dialaminya.

Tabel 5. Estimasi Perhitungan Nilai Tekanan Psikologis Pekerja Akibat Kemacetan

\begin{tabular}{lr}
\hline \multicolumn{1}{c}{ Komponen } & \multicolumn{1}{c}{ Nilai } \\
\hline Tingkat pekerja yang mengalami tekanan psikologis dan melakukan liburan & $37,62 \%$ \\
Jumlah pekerja di Sudirman (orang) & 132.000 \\
Rata-Rata biaya liburan yang dikeluarkan selama 1 tahun & 10.588 .608 \\
\hline Nilai tekanan psikologis dari pekerja (Rp/tahun) & $\mathbf{5 2 5 . 8 0 0 . 0 0 0 . 0 0 0}$ \\
\hline
\end{tabular}

Sumber: Data Primer, 2013 (diolah)

\section{Total Kerugian Ekonomi Dampak Kemacetan}

Kemacetan telah memberikan dampak negatif bagi kehidupan manusia. Besarnya dampak negatif tersebut sebagian dapat dirasakan dengan peningkatan biaya, sebagian lagi tidak dirasakan secara langsung seperti terserangnya Penyakit ISPA. Berdasarkan hasil perhitungan beberapa komponen kerugian yang diderita oleh masyarakat maka akan didapatkan nilai total seperti terlihat pada Tabel 6 .

Tabel 6.Total Kerugian Ekonomi Dampak Kemacetan

\begin{tabular}{clc}
\hline No & \multicolumn{1}{c}{ Kerugian Ekonomi } & Nilai Kerugian Per Tahun (Rp) \\
\hline 1 & Nilai Inefisiensi Bahan Bakar Motor (BBM) & 15.008 .423 .787 .414 \\
2 & Nilai Penurunan Produktivitas Pekerja & 2.871 .644 .285 .714 \\
3 & Nilai Stress akibat Macet & 525.800 .000 .000 \\
4 & Nilai Kesehatan & 1.310 .371 .500 .000 \\
\hline & \multicolumn{1}{c}{ TOTAL KERUGIAN EKONOMI } & $\mathbf{1 9 . 7 1 6 . 2 3 9 . 5 7 3 . 1 2 8}$ \\
\hline
\end{tabular}

Sumber: Data primer diolah, 2013

Jumlah kerugian ekonomi akibat dampak kemacetan di Jl. Jenderal Sudirman sebesar Rp. 19.716.239.573.128/tahun. Kerugian tersebut jauh akan lebih besar jika ditambahkan dampak ikutan atau multiplayer effect dari kerugian-kerugian yang ada.

\section{SIMPULAN DAN SARAN}

Kerugian total ekonomi akibat dampak kemacetan di Jl. Jenderal $80 \quad$ Sudirman sebesar Rp 19.716.239.573.128 per tahun. Kerugian tersebut berasal dari nilai inefisiensi Bahan Bakar Motor (BBM) Rp 15.008.423.787.414/tahun, nilai penurunan produktivitas pekerja $\mathrm{Rp}$ 2.871.644.285.714/tahun, nilai tekanan psikologis akibat kemacetan Rp 525.800.000.000/tahun, dan nilai kesehatan Rp 1.310.371.500.000/tahun.

Penanganan kemacetan harus segera dilakukan, hal ini dikarenakan nilai kerugian yang cukup besar. Penanganan kemacetan haruslah dimulai dari singkronisasi antar kebijakan dan penegakan aturan yang ada. Pilihan kebijakan pembatasan akses masuk ke Jl. Jenderal Sudirman melalui penggunaan Electronic Road Pricing (ERP) dirasa lebih tepat dibandingkan kebijakan penanganan kemacetan lainnya. 


\section{DAFTAR PUSTAKA}

Badan Pusat Statistik 2010. "Produksi Kendaraan Bermotor untuk Kuartal II ${ }^{\text {ee }}$. Badan Pusat Statistik. Jakarta.

Falatehan. F. A, Sri Mulyono, dan Adrianus Siswanto. 2010. Pemilihan Kebijakan Mengatasi Kemacetan Lalu Lintas Di Kota Bogor dengan Pendekatan Analitical Hirarchy Process(AHP). Warta Penelitian Perhubungan. Volume 22, Nomor 2/ 2010

Pradeep K Gulipalli dan Kara M. Kockelman. 2008 Credit-based congestion pricing: A Dallas-Fort Worth application. Transport Policy 15 (2008) 23-32

Wardhana, W. A. 2004. Dampak Pencemaran Lingkungan (Edisi Revisi). Andi Offset. Yogyakarta. 